\title{
Comparative Bioremediation of Crude Oil-Amended Tropical Soil Microcosms by Natural Attenuation, Bioaugmentation, or Bioenrichment
}

\author{
Vanessa Marques Alvarez, Joana Montezano Marques, \\ Elisa Korenblum, and Lucy Seldin
}

Laboratório de Genética Microbiana, Departamento de Microbiologia Geral, Instituto de Microbiologia Prof. Paulo de Góes (IMPPG), Universidade Federal do Rio de Janeiro, Centro de Ciências da Saúde, Bloco I, Ilha do Fundão, CEP 21941-590, Rio de Janeiro, Brazil

Correspondence should be addressed to Lucy Seldin, lseldin@micro.ufrj.br

Received 15 February 2011; Revised 31 March 2011; Accepted 18 April 2011

Academic Editor: Wen-Jun Li

Copyright (C) 2011 Vanessa Marques Alvarez et al. This is an open access article distributed under the Creative Commons Attribution License, which permits unrestricted use, distribution, and reproduction in any medium, provided the original work is properly cited.

\begin{abstract}
Bioremediation is an efficient strategy for cleaning up sites contaminated with organic pollutants. In this study, we evaluated the effectiveness of monitored natural attenuation, bioenrichment, and bioaugmentation using a consortium of three actinomycetes strains in remediating two distinct typical Brazilian soils from the Atlantic Forest and Cerrado biomes that were contaminated with crude oil, with or without the addition of $\mathrm{NaCl}$. Microcosms were used to simulate bioremediation treatments over a 120day period. During this period, we monitored total petroleum hydrocarbons (TPHs) and n-alkanes degradation and changes in bacterial communities. Over time, we found the degradation rate of $n$-alkanes was higher than TPH in both soils, independent of the treatment used. In fact, our data show that the total bacterial community in the soils was mainly affected by the experimental period of time, while the type of bioremediation treatment used was the main factor influencing the actinomycetes populations in both soils. Based on these data, we conclude that monitored natural attenuation is the best strategy for remediation of the two tropical soils studied, with or without salt addition.
\end{abstract}

\section{Introduction}

The high demand for and use of petroleum and its derivatives worldwide has made petroleum hydrocarbon contamination a global problem with serious health and environmental consequences [1-3].

Contamination of soil and groundwater with petroleum compounds is frequently observed, necessitating the development of innovative technologies for remediation $[4,5]$.

Bioremediation is an efficient and environmentally friendly technology for long-term restoration of sites contaminated with petroleum hydrocarbons and derivatives $[5,6]$. Several studies have focused on the composition of naturally occurring microbial populations that contribute to biodegradation of petroleum and its derivatives in different environments [7-10]. Monitored natural attenuation (MNA) uses the ability of the soil intrinsic microbial community to degrade the contaminant. In cases where enhancement of the soil microbial community is deemed necessary, either bioaugmentation or bioenrichment is used. Bioaugmentation relies upon pollutant-degrading microorganisms found in the contaminated site, whereas in bioenrichment the microorganisms are exogenous [11, 12]. Regardless, studies of both approaches have demonstrated that the degrading organisms are not maintained in the contaminated environment after introduction [13, 14]. Therefore, molecular methods that rapidly survey the microbial community structure and function [15] are being employed extensively to monitor both the persistence of the microbial inocula added to the contaminated site and the effects of the introduced microorganisms upon the indigenous microbiota [16].

Actinomycetes have been widely used in bioremediation in soils contaminated with petroleum and derivatives 
$[5,17,18]$. Actinomycetes have several characteristics that are essential for this ability: they are excellent metabolizers, they are able to survive in extreme conditions such as dry environments or under nutrient starvation, and they produce biosurfactants, which increase contaminant biodisponibility and facilitate biodegradation process.

In a previous study, Alvarez et al. [19] isolated 14 halotolerant actinobacterial strains from a soil contaminated with crude oil and produced water sampled at Panelas, a terrestrial oil field in Brazil. The environment impact of the oil contamination was exacerbated by the presence of moderate salt concentration (around $7 \% \mathrm{NaCl}$ ) in the produced water. All 14 strains showed the ability to degrade crude oil and some oil derivatives [19]. However, these strains were not tested for their ability to degrade oil in a mixed microbial consortium. In this study, we consider the application of these strains for soil bioremediation after crude oil contamination in the Brazilian oil field area studied, Panelas and another site, Cantagalo. Specifically, we aim to (a) select a bacterial consortium from the previously isolated strains based on their growth capabilities and degradation profiles; (b) set up soil microcosms using two representative soils from Brazilian biomes, Cantagalo soil from the Atlantic Forest and Panelas soil from Cerrado, with or without the addition of salt; (c) compare the efficiency of monitored natural attenuation, bioaugmentation, or bioenrichment during a 120-day experiment; and (d) analyze the effect of each bioremediation treatment on total bacterial community and actinomycetes population by $16 \mathrm{~S}$ rRNA-based PCR and denaturing gradient gel electrophoresis (DGGE). The results of this study will be of great use, given that oil spills may occur in the Brazilian areas studied, leading to environmental impacts in either Cerrado or Atlantic Forest biomes. Moreover, monitoring the persistence of the bacterial inocula added to the contaminated site and its effects upon the indigenous microbiota can provide main tools for future use of these bacteria.

\section{Materials and Methods}

2.1. Bacterial Strains. We chose seven of the 14 halotolerant actinobacterial strains identified in Alvarez et al. [19] for use in this study based upon their ability to degrade crude oil and petroleum derivatives in Bushnell-Haas (BH, Difco) medium containing $7 \% \mathrm{NaCl}$, their growth in mineral medium using crude oil as the sole source of carbon, and their ease of maintenance under laboratory conditions (Table 1).

\subsection{Total Petroleum Hydrocarbons (TPH) and n-Alkanes} Degradation Analyses. All seven selected strains were grown for 30 days at $28^{\circ} \mathrm{C}$ in $20 \mathrm{~mL}$ of $\mathrm{BH}$ medium with $7 \% \mathrm{NaCl}$ and 1,000 ppm crude oil. TPH and n-alkanes concentrations were determined using the EPA 8015 C technique [20].

2.3. Soil Microcosms. Two 3-kg pristine soil samples were collected from the Atlantic Forest and Cerrado biomes in Brazil. The Atlantic Forest soil was sampled from a farm located in Cantagalo city at Rio de Janeiro state (latitude $21^{\circ} 58^{\prime} 52^{\prime \prime}$ and longitude $42^{\circ} 22^{\prime} 05^{\prime \prime}$-Southeast Brazil). The Cerrado soil sample was obtained near an oil field area in Panelas located at Carmópolis City, Sergipe state (latitude $10^{\circ} 38^{\prime} 53^{\prime \prime}$ and longitude $36^{\circ} 59^{\prime} 20^{\prime \prime}$ - Northeast Brazil). Characteristics of each soil are detailed in Table 2.

In order to set up our microcosms of each soil, two portions of $684 \mathrm{~g}$ of each soil were contaminated with $36 \mathrm{~g}$ $(50,000 \mathrm{ppm})$ of crude oil from the Panelas oil field. The first portion was then subdivided into two equal parts of $360 \mathrm{~g}$ each. One $360 \mathrm{~g}$ portion was supplemented with $21 \mathrm{~mL}$ of a $0.85 \% \mathrm{NaCl}$ solution. The soil was then homogenized and distributed between three polyvinyl chloride (PVC) pots (25 cm in circumference, $8 \mathrm{~cm}$ in diameter and $12 \mathrm{~cm}$ high) lined with aluminum foil and plastic. These pots simulated a monitored natural attenuation (MNA) treatment in both soils without the addition of $\mathrm{NaCl}$. The other $360 \mathrm{~g}$ portion was supplemented with $21 \mathrm{~mL}$ of a $0.85 \% \mathrm{NaCl}$ solution and $10^{8} \mathrm{CFU} / \mathrm{mL}$ of the bacterial consortium. The soil was then homogenized and distributed between three PVC pots. To prepare the bacterial consortium inoculum, the strains $G$. rubripectinta DTSB 2.5, R. equi DLB 2.6, and G. alkanivorans DLB 3.22 were grown separately at $28^{\circ} \mathrm{C}$ for $72 \mathrm{~h}$ in $20 \mathrm{~mL}$ of LB medium (tryptone $1 \%$, yeast extract $0.5 \%, \mathrm{NaCl} 0.5 \%$ ) with crude oil $(20 \mu \mathrm{L})$. Each strain was then inoculated in an Erlenmeyer containing $180 \mathrm{~mL}$ of LB medium and grown at $28^{\circ} \mathrm{C}$ for $72 \mathrm{~h}$. The resultant cells were washed three times with saline $(\mathrm{NaCl} 0.85 \%)$ before inoculation, and $100 \mu \mathrm{L}$ was used to determine the CFU/mL. The other $360 \mathrm{~g}$ portion of soil was prepared identically; however, a $7 \% \mathrm{NaCl}$ solution was used instead. Microcosms were incubated for 120 days at room temperature. The pots were watered based on the water holding capacity of the soil and revolved for aeration twice a week.

In the case of soil from Panelas, the soil inoculated with bacteria represented bioaugmentation-BA (no salt) or BAS (salt). Conversely, soil from Cantagalo inoculated with bacteria represented bioenrichment-BE (no salt) or BES (salt). The microcosms submitted to MNA with salt were denoted MNAS.

2.4. Soil Petroleum Hydrocarbons and n-Alkanes Analyses. Composite samples were obtained for each bioremediation treatment by mixing $4 \mathrm{~g}$ of soil obtained from each triplicate. Total petroleum hydrocarbons (TPHs) and nalkanes concentrations were determined by gas chromatography using the EPA $8015 \mathrm{D}$ technique [22]. Percentages of degradation were calculated using the n-alkanes and $\mathrm{TPH}$ values obtained in T0 and T120 for each bioremediation treatment by the following expressions: percentage of $\mathrm{TPH}$ degradation $=\left[\left(\mathrm{TPH}_{\mathrm{T} 0}-\mathrm{TPH}_{\mathrm{T} 120}\right) / \mathrm{TPH}_{\mathrm{T} 0}\right] \times 100$ or percentage of $\mathrm{n}$-alkanes degradation $=\left[\right.$ alkanes $_{\mathrm{T} 0}-$ alkanes $_{\mathrm{T} 120}$ )/alkanes $\left.\mathrm{T}_{\mathrm{T} 0}\right] \times 100$. The efficiencies of bioenrichment and bioaugmentation were compared to those observed for monitored natural attenuation as follows: efficiency of BE/BA for TPH degradation = percentage of $\mathrm{TPH}$ degradation using $\mathrm{BE} / \mathrm{BA}$ - percentage of TPH degradation using MNA Cantagalo/MNA Panelas. 


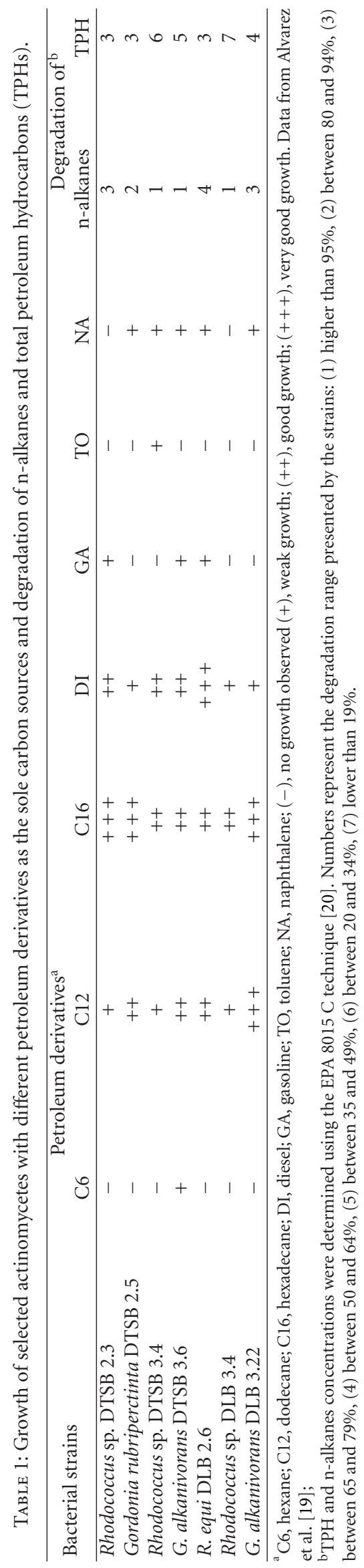


TABle 2: Physical and chemical characteristics of Cantagalo and Panelas soils.

\begin{tabular}{lcc}
\hline Soil property & Cantagalo/ RJ & Panelas/SE \\
\hline $\mathrm{pH}$ & 6.3 & 4.6 \\
$\mathrm{P}\left(\mathrm{mg} \mathrm{dm}^{-3}\right)$ & 13 & 6 \\
$\mathrm{~K}\left(\mathrm{mmol}^{\mathrm{c}} \mathrm{dm}^{-3}\right)$ & 7 & 2.2 \\
$\mathrm{Ca}\left(\mathrm{mmol}^{\mathrm{c}} \mathrm{dm}^{-3}\right)$ & 43.3 & 27 \\
$\mathrm{Mg}\left(\mathrm{mmol}^{\mathrm{c}} \mathrm{dm}^{-3}\right)$ & 38.5 & 12 \\
$\mathrm{Al}\left(\mathrm{mmol}^{\mathrm{c}} \mathrm{dm}^{-3}\right)$ & 0 & 3 \\
$\mathrm{H}+\mathrm{Al}\left(\mathrm{mmol}^{\mathrm{c}} \mathrm{dm}^{-3}\right)$ & 35.3 & 85 \\
$\mathrm{Na}\left(\mathrm{mmol}^{\mathrm{c}} \mathrm{dm}^{-3}\right)$ & 0.6 & 1.7 \\
$\mathrm{~V}(\%)^{\mathrm{a}}$ & 72 & 34 \\
$\mathrm{~m}(\%)^{\mathrm{b}}$ & 0 & 2.3 \\
$\mathrm{ISNa}(\%)^{\mathrm{c}}$ & 0 & 1 \\
$\mathrm{Fe}\left(\mathrm{mg} \mathrm{dm}^{-3}\right)$ & 35.33 & 312 \\
$\mathrm{Cu}\left(\mathrm{mg} \mathrm{dm}^{-3}\right)$ & 0.42 & 0.8 \\
$\mathrm{Zn}\left(\mathrm{mg} \mathrm{dm}^{-3}\right)$ & 5.45 & 2 \\
$\mathrm{Mn}(\mathrm{mg} \mathrm{dm}$ & \\
Sand $(\%)$ & 98.97 & 3.8 \\
Silt $(\%)$ & 76 & 66 \\
Clay $(\%)$ & 8 & 12 \\
Classification & 16 & 22 \\
\hline
\end{tabular}

${ }^{a}$ Bases saturation index; ${ }^{b}$ aluminum saturation index; ${ }^{c}$ sodium saturation index. ${ }^{d}$ trilinear soil classification was made according with the percentages of sand, silt, and clay [21].

2.5. DNA Extraction. The oil-contaminated soil microcosms were sampled at $0,30,60,90$, and 120 days for molecular analyses. Soil samples of $0.5 \mathrm{~g}$ were taken from each triplicate under different bioremediation treatments. Total DNA was extracted from these soil samples using the Fast DNA Spin Kit for Soil (Qbiogene, BIO 101 Systems, USA) according to the manufacturer's instructions. DNA was extracted from the bacterial strains used in the consortium using the methodology described by Seldin and Dubnau [23]. DNAs were visualized on $0.8 \%(\mathrm{w} / \mathrm{v})$ agarose gels to assess their integrity and then stored at $4^{\circ} \mathrm{C}$ prior to their use in PCR reactions.

2.6. PCR Amplification of Bacterial 16S rRNA Genes. A $473 \mathrm{bp}$ fragment of the bacterial 16S rRNA gene was amplified using PCR primers U968F-GC1 and 1401R [24]. The $50-\mu \mathrm{L}$ PCR reaction mix contained $1 \mu \mathrm{L}$ of template DNA (corresponding to 50-100 ng), 1x Colorless GoTaq Flexi Buffer, pH 8.5 (Promega, Madison, WI, USA), $5 \mathrm{mM}$ $\mathrm{MgCl}_{2}, 200 \mu \mathrm{mol}$ of each dNTPs, $20 \rho \mathrm{mol}$ of each primer, $5 \mu \mathrm{g}$ of bovine serum albumin (BSA), and $2.5 \mathrm{U}$ of Taq polymerase. Amplification conditions were previously described by Nübel et al. [25]. Negative controls without DNA were run in all amplifications. PCR products were visualized by electrophoresis on $1.4 \%$ agarose gels stained with ethidium bromide $(2 \mu \mathrm{g} / \mathrm{mL})$. Amplicons were stored at $-20^{\circ} \mathrm{C}$ until DGGE analysis.

2.7. PCR Amplification of Actinomycetes $16 S$ rRNA Genes. For specific amplification of $16 \mathrm{~S}$ rRNA gene fragments from actinomycetes, the primers F243 (5' GGATGAGCCCGCGGCCTA 3'), U968F-GC1 (5' ACCGCGAAGAACCTTAC 3') and 1401R (5' GCGTGTGTACAAGACCC $3^{\prime}$ ), were used in a two-step nested PCR [26]. The $25 \mu \mathrm{L}$ PCR reaction mixture contained 1x Colorless GoTaq Flexi Buffer ( $\mathrm{pH}$ 8.5), $2.5 \mathrm{mM}$ $\mathrm{MgCl}_{2}, 200 \mu \mathrm{mol}$ of each dNTPs, $100 \mathrm{nM}$ of each primer (F243 and 1401R), $1 \mu \mathrm{L}$ of DNA template, and $1.25 \mathrm{U}$ of Taq polymerase. Amplification conditions were as follows: initial denaturation for $5 \mathrm{~min}$ at $94^{\circ} \mathrm{C}$; 35 cycles using $1 \mathrm{~min}$ of denaturation at $94^{\circ} \mathrm{C}, 1 \mathrm{~min}$ at $58^{\circ} \mathrm{C}$ for primer annealing, and $2 \mathrm{~min}$ at $72^{\circ} \mathrm{C}$ for primer extension; a final extension for $10 \mathrm{~min}$ at $72^{\circ} \mathrm{C}$; cooling to $4^{\circ} \mathrm{C}$. Expected fragments of $1158 \mathrm{bp}$ were visualized by electrophoresis on $1.4 \%$ agarose gels stained with ethidium bromide $(2 \mu \mathrm{g} / \mathrm{mL})$ and then used as templates for the second amplification. The second reaction was performed as described above using the primers U968F-GC1 and 1401R.

2.8. Denaturing Gradient Gel Electrophoresis (DGGE). DGGE using 16S rRNA gene PCR products obtained either from total bacterial communities or from the specific populations of actinomycetes was performed using a Dcode Universal Mutation Detection System (Bio-Rad, Calif, USA). PCR amplicons were loaded directly onto a $8 \%(\mathrm{w} / \mathrm{v})$ polyacrylamide gel containing a denaturing gradient of urea and formamide varying from $40 \%$ to $70 \%$ in $1 x$ TAE buffer $(40 \mathrm{mM}$ Tris-acetate ( $\mathrm{pH} 7.4), 20 \mathrm{mM}$ sodium acetate, and $1 \mathrm{mM}$ disodium EDTA). DGGE was run for $16 \mathrm{~h}$ at $60^{\circ} \mathrm{C}$ and $75 \mathrm{~V}$ and then stained with SYBR-Green I (Invitrogen-Molecular Probes, SP, Brazil) for $40 \mathrm{~min}$. Stained gel was visualized under UV light and digitized using STORM (Amersham Pharmacia Biotech, Munich, Germany). Clustering patterns of different profiles from DGGE were obtained using GelCompar II 4.06 software (Applied Maths, Saint MartensLatem, Belgium), Pearson's coefficient and the clustering method of unweighted pair-group method using arithmetic averages (UPGMA).

2.9. Canonical Correspondence Analysis (CCA). Canonical correspondence analysis (CCA) was used to correlate DGGE profiles (biological variables) with environmental variables (sampling time-T0, T60, and T120, bioremediation treatment, $\mathrm{NaCl}$ addition, and $\mathrm{TPH}$ and n-alkanes degradation). CCA was also used to cluster DGGE profiles obtained after 120 days of bioremediation experiment with the physical and chemical composition of soils used (Cantagalo and Panelas). CCA was performed using Canoco for Windows 4.5 (Microcomputer Power, Ithaca, NY).

\section{Results}

3.1. Consortium Selection. We chose to study seven of the 14 halotolerant actinomycetes strains previously isolated from Panelas, a tropical soil-containing area from the northeast of Brazil, which is described by Alvarez et al. [19]. Strains were chosen based on their profiles of degradation of petroleum derivatives (Table 1) and good growth and maintenance under laboratory conditions. They were first tested for 
TABLE 3: Degradation rates of $n$-alkanes and $\mathrm{TPH}$ for each bioremediation treatment.

\begin{tabular}{lccc}
\hline Soil & $\begin{array}{c}\text { Bioremediation } \\
\text { treatment }^{\mathrm{a}}\end{array}$ & $\begin{array}{c}\text { n-alkanes } \\
\text { degradation (\%) }\end{array}$ & $\begin{array}{c}\text { TPH } \\
\text { degradation (\%) }\end{array}$ \\
\hline \multirow{6}{*}{ Cantagalo } & MNA & 56.5 & 15.6 \\
& MNAS & 64.8 & 32.5 \\
& BE & 60 & 24.8 \\
\multirow{4}{*}{ Panelas } & BES & 67.7 & 36.2 \\
& MNA & 74 & 38.1 \\
& BNAS & 78.1 & 39.3 \\
& BAS & 78.4 & 47.5 \\
\hline
\end{tabular}

aNA, monitored natural attenuation; MNAS, monitored natural attenuation in soil with the addition of $\mathrm{NaCl}$; $\mathrm{BE}$, bioenrichment; $\mathrm{BES}$, bioenrichment in soil with $\mathrm{NaCl}$; BA, bioaugmentation; BAS, bioaugmentation in soil with $\mathrm{NaCl}$.

TPH and n-alkanes degradation after growth in medium containing $7 \%$ of $\mathrm{NaCl}$. All strains tested showed n-alkanes degradation rates of at least 50\% (Table 1). Strains DTSB 3.4, DTSB 3.6, and DLB 3.4 almost reached 100\% degradation (Table 1). Conversely, TPH degradation rates were lower than those observed for $\mathrm{n}$-alkanes, ranging from 10 to $70 \%$. The best rates of $\mathrm{TPH}$ degradation (60 to 70\%) were observed in the DLB 3.22, DTSB 2.3, DLB 2.6, and DTSB 2.5 strains (Table 1 ). These strains were previously identified as Gordonia alkanivorans (DLB 3.22), Rhodococcus sp. (DTSB 2.3), R. equi (DLB 2.6), and G. rubriperctinta (DTSB 2.5) [19]. After initial testing, DLB 3.22, DTSB 2.3, and DLB 2.6 were chosen to represent the bacterial consortium due to their broad profiles of degradation of petroleum derivatives and good rates of n-alkanes and TPH degradation. Strain DTSB 2.3 was excluded from the consortium because it showed a degradation profile similar to DTSB 2.5, except that it lacked the ability to use naphthalene as a sole carbon source (Table 1).

3.2. Crude Oil Contamination Assay. We conducted three different bioremediation treatments in microcosms to evaluate the efficiency of crude oil degradation in artificially contaminated soils. We assessed the following treatments both in the presence or absence of salt: (a) monitored natural attenuation (MNA) of both soils; (b) bioenrichment (BE) used specifically in Cantagalo soil; (c) bioaugmentation (BA) used in Panelas soil. After 120 days, the degradation rates of n-alkanes were higher than the rates of TPH degradation in all treatment scenarios and in both soils (Table 3). However, degradation of $n$-alkanes and TPH in the Panelas soil microcosms were higher than those of the Cantagalo soil. Bioenrichment (BE and BES) and bioaugmentation (BA and BAS) resulted in a slight increase in the biodegradation rates of both n-alkanes and TPH when compared to monitored natural attenuation (MNA and MNAS) (Table 3). There was no considerable difference in the efficiency of n-alkanes degradation by bioenrichment treatment with or without the addition of salt. However, the addition of salt resulted in differences in TPH degradation efficiency. The efficiency of bioenrichment treatment in Cantagalo soil decreased from $9 \%(\mathrm{BE})$ to $4 \%(\mathrm{BES})$ in the presence of salt, whereas the efficiency of bioaugmentation in Panelas soil increased from $9 \%$ (BA) to $12 \%$ (BAS) when salt was added (Table 3 ).

3.3. Molecular Analysis of Total Bacterial Communities and Actinomycetes. Native bacterial and actinomycetes consortium DNA was recovered from the soil microcosms at 0,30 , 60,90 , and 120 days (for each bioremediation treatment) and then subjected to PCR to amplify a 473 bp band corresponding to the $16 \mathrm{~S}$ rRNA encoding gene. DGGE fingerprints were also generated for each sample producing consistent DGGE profiles among triplicate samples (data not shown). The composition of the bacterial communities from Cantagalo and Panelas soils changed throughout the course of the bioremediation treatments (Figures 1(a) and 1(b)) although DGGE bands corresponding to the bacterial consortium could be observed in all bioenriched or bioaugmented samples, with or without the addition of $\mathrm{NaCl}$ (Figures $1(\mathrm{a})$ and $1(\mathrm{~b}))$. Clustering DGGE pattern profiles of the total bacterial communities showed that the duration of the bioremediation experiment was the main factor affecting total bacterial communities in both soils (Figures 1(c) and 1(d)). In Cantagalo soil, two main clusters were formed with $70 \%$ similarity: one formed by time 0 and the other from the 30-, 60-, 90-, and 120-day samples. The 30- and 60-day samples showed the most similarity to each other, $87 \%$. In Panelas soil, two clusters showed $78 \%$ of similarity: one was formed by times 0,30 , and 60 days and the other by 90 and 120 days.

Actinomycetes populations present in both soils studied also varied throughout the bioremediation experiment (Figures 2(a) and 2(b)). However, in this case, the bioremediation treatment, rather than time as in the case of total bacterial community, was the main factor influencing changes in the actinomycetes populations from both soils. In Cantagalo soil, actinomycetes populations experienced an initial negative impact on their growth rate until day 60, likely due to oil contamination of soil. However, after 90 days (T90 and T120), the intensity of preexisting bands increased, and new bands were observed (Figure 2(a)). No significant changes were visualized between the $\mathrm{BE}$ and BES treatments of Cantagalo soil. The main difference between bioenrichment and MNA/MNAS was the presence of the bacterial consortium corresponding bands, plotted on a dendrogram (Figure 2(c)). DGGE profiles of BE and BES treatments were $78 \%$ similar to the MNA and MNAS treatment profiles. Moreover, the 90- and 120-day samples from MNA and MNAS were $72 \%$ similar to all of the remaining samples.

In Panelas soil, MNA and MNAS treatments did not vary much from each other during the entire 120-day experiment (Figure 2(b)). In BAS treatment conditions, the bacterial consortium corresponding bands were initially weak and not detectable at day 0 in DGGE. However, from day 30 to 120 , the bacterial consortium bands became intense and were easily detectable (Figure 2(b)). The visual interpretation of these DGGE profiles was confirmed through plotting of a dendrogram of the actinomycetes populations in Panelas 


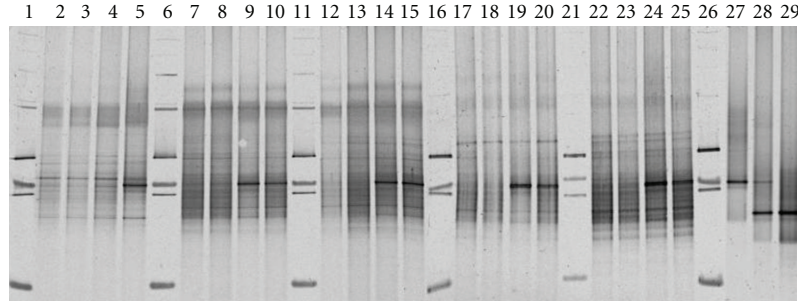

(a)

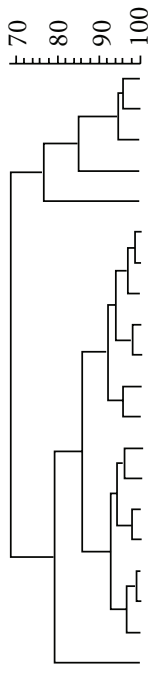

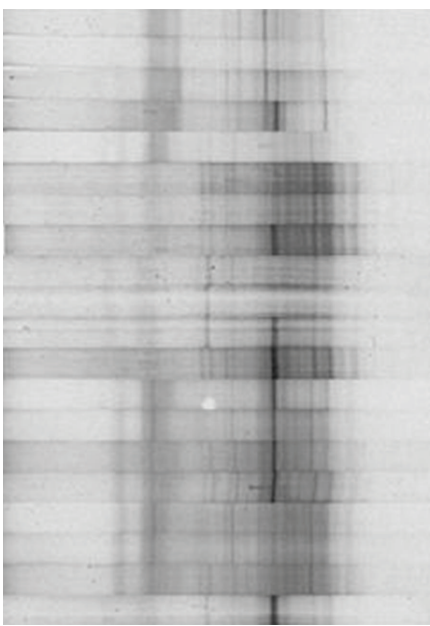

(c)

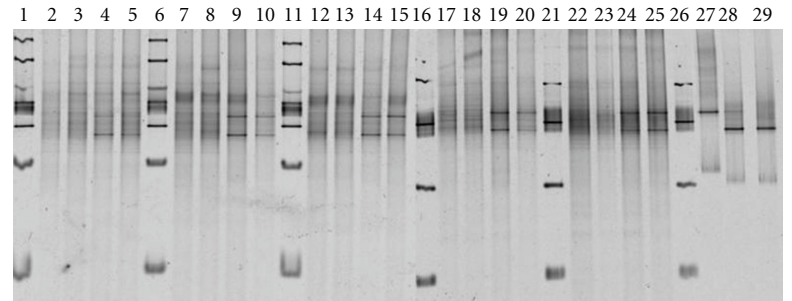

(b)

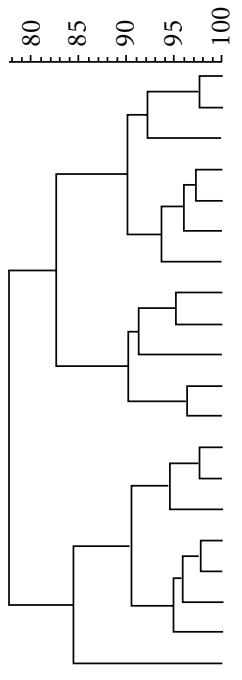

MNA T60 MNAS T60 MNA T30 MNAS T0 BA T0 MNAS T30 MNA T0 BA T30 BAS T60 BAS T30 BA T0 BA T60 MNA T120 MNAS T120 MNA T90 BA T120 BAS T120 BAS T90 BA T90

(d) MNAS T90

FIGURE 1: Denaturing gradient gel electrophoresis (DGGE) fingerprints of bacterial 16S rRNA gene fragments amplified from Cantagalo (a) and Panelas (b) microcosms submitted to different bioremediation treatments and sampled after 0, 30, 60, 90, and 120 days. Lanes: (1, 6, 11, 16, 21 and 26) $1 \mathrm{~Kb}$ ladder, (2) MNA T0, (3) MNAS T0, (4) BE/BA T0, (5) BES/BAS T0, (7) MNA T30, (8) MNAS T30, (9) BE/BA T30, (10) BES/BAS T30, (12) MNA T60, (13) MNAS T60, (14) BE/BA T60, (15) BES/BAS T60, (17) MNA T90, (18) MNAS T90, (19) BE/BA T90, (20) BES/BAS T90, (22) MNA T120, (23) MNAS T120, (24) BE/BA T120, and (25) BES/BAS T120. Strains used for the bacterial consortium: (27) Gordonia alkanivorans DLB 3.22, (28) G. rubriperctinta DTSB 2.5, and (29) Rhodococcus equi DLB 2.6. GelCompar II 4.06 software was used to generate the dendrogram based on the DGGE clustering profiles of the soils from Cantagalo (c) and Panelas (d) using Pearson's coefficient and the clustering method of UPGMA.

soil (Figure 2(d)). This dendrogram shows that BAS T0 was $45 \%$ similar to the major cluster of all other samples. Furthermore, all samples from bioaugmentation (BA and BAS, except BAS T0) and all samples from monitored natural attenuation (MNA and MNAS) were $65 \%$ similar to each other. Further subgrouping formed between the treatments with and without the addition of $\mathrm{NaCl}(\mathrm{MNA} \times$ MNAS and $B A \times B A S)$ can be seen in Figure 2(d).

3.4. Canonical Correspondence Analysis. CCA analysis of both soils corroborated the results obtained from clustering the DGGE profiles. This analysis showed that the separation of these profiles was determined by the amount of time they were submitted to bioremediation treatment, as seen when these sample profiles were plotted by axis 1 with a high degree of variability, $87.6 \%$ in Cantagalo soil (Figure 3(a)) and $52.8 \%$ in Panelas soil (Figure 3(b)). In the Cantagalo soil CCA analysis, axis 2 separated DGGE profiles of microcosms with added $\mathrm{NaCl}$ from those without $\mathrm{NaCl}$ with a $12.4 \%$ variability. Moreover, the environmental variables of TPH and n-alkanes degradation were correlated with the points corresponding to T60 and T120 in the soil from Cantagalo, particularly with those soils which had additional salt (BES T60 and BES T120, corresponding to points 11 and 12). In Panelas soil, axis 2 separated DGGE profiles according to the type of bioremediation treatment used. Points representing MNA (points 2 and 3) and MNAS (points 5 and 6) were separated from points representing BA (points 8 and 9) and BAS (points 11 and 12 ) with $47.2 \%$ variability. The environmental variables of TPH and n-alkanes degradation were correlated to points of 60 and 120 days (with the exception of points 2 and 5 representing MNAS T60 and MNA T60), similar to what was seen with Cantagalo soil.

CCA analysis was also used to correlate the DGGE profiles of all bacterial communities from T120 related to Cantagalo and Panelas soils with the physical and chemical properties of each soil (Figure 4). After 120 days of bioremediation, the points representing the Cantagalo soil profiles (points 1,2,3, and 4) were separated from points representing Panelas soil profiles (points 5, 6, 7, 


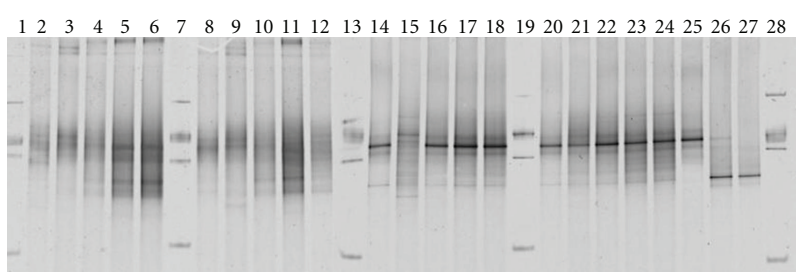

(a)

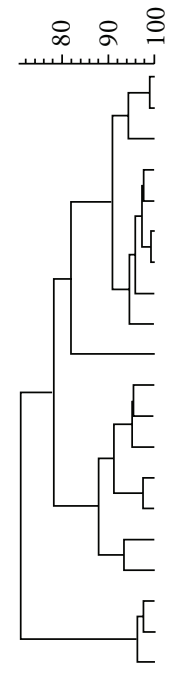

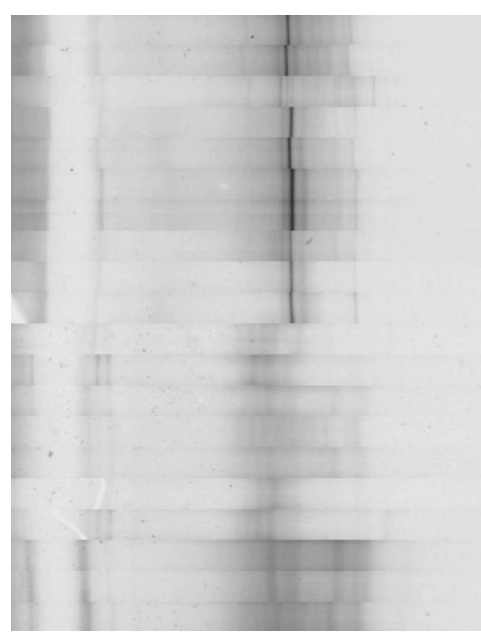

(c)

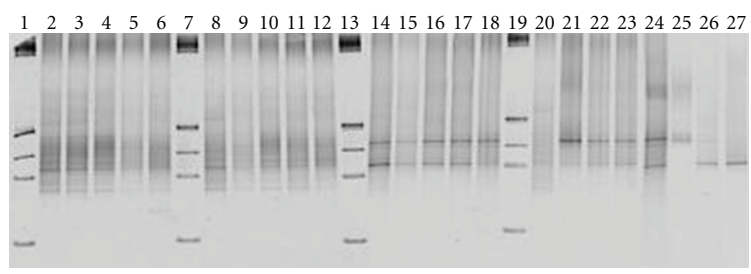

(b)

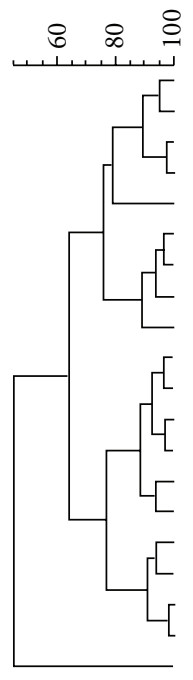

BA T0

BA T30

BA T60

BA T90

BA T120

BAS T30

BAS T60

BAS T90

BAS T120

MNA T90

MNA T120

MNA T30

MNA T60

MNA T0

MNAS T0

MNAS T30

MNAS T60

MNAS T90

MNAS T120

BAS T0

(d)

Figure 2: Denaturing gradient gel electrophoresis (DGGE) fingerprints of actinomycetes populations from Cantagalo (a) and Panelas (b) microcosms submitted to different bioremediation treatments and sampled after 0, 30, 60, 90, and 120 days. Lanes: (1, 7, 13, 19 and 28) $1 \mathrm{~Kb}$ ladder, (2) MNA T0, (3) MNA T30, (4) MNA T60, (5) MNA T90, (6) MNA T120, (8) MNAS T0, (9) MNAS T30, (10) MNAS T60, (11) MNAS T90, (12) MNAS T120, (14) BE/BA T0, (15) BE/BA T30, (16) BE/BA T60, (17) BE/BA T90, (18) BE/BA T120, (20) BES/BAS T0, (21) BES/BAS T30, (22) BES/BAS T60, (23) BES/BAS T90, and (24) BES/BAS T120. Strains used for the bacterial consortium: (25) Gordonia alkanivorans DLB 3.22, (26) G. rubriperctinta DTSB 2.5, and (27) Rhodococcus equi DLB 2.6. Dendrogram based on the DGGE clustering profiles of the soils from Cantagalo (c) and Panelas (d) using Pearson's coefficient and the clustering method of UPGMA.

and 8), independent of the bioremediation treatment used. This separation pattern was influenced by environmental variables such as the physical and chemical composition of soils (represented by vectors). The separation of MNAS and BA treatments of Panelas soil (points 6 and 7) from the other treatments was due to a strong correlation with TPH and nalkanes degradation variables.

\section{Discussion}

Bioaugmentation and bioenrichment are successful technologies for bioremediation in sites that lack significant microbial populations capable of degrading petroleum and its derivatives [27-29]. However, choosing efficient biodegraders for inoculation is not an easy task. In this study, three actinomycetes strains were chosen to be used for either bioaugmentation or bioenrichment of two different Brazilian soils that were artificially contaminated with crude oil and supplemented or not with $\mathrm{NaCl}$. Two of the strains belonged to the genus Gordonia (G. rubriperctinta and G. alkanivorans) and one to Rhodococcus ( $R$. equi). Our choice was reinforced by data demonstrating that actinomycetes can degrade n-alkanes and show great potential for bioremediation [10]. Specifically, Gordonia have the ability to degrade or modify aliphatic hydrocarbons [30], and Rhodococcus can degrade petroleum hydrocarbons and their derivatives $[31,32]$. Moreover, actinomycetes are known to grow even under restrictive conditions and can persist in unfavorable environments for long periods of time [33].

During the bioremediation experiments, n-alkane and TPH degradation rates were determined under all conditions. Naturally occurring microbial communities from the Panelas soil sample were more effective in $\mathrm{n}$-alkanes and TPH degradation than those found in the Cantagalo soil sample. Therefore, bioaugmentation using indigenous halotolerant bacterial strains may be a good strategy to treat oilcontaminated Panelas soil because indigenous microorganisms usually adapt more easily during reintroduction to their native soils [7]. Similarly, Zhuang et al. [34] demonstrated that bioremediation of saline soils and wastewaters were possible with the addition of halotolerant microorganisms.

We analyzed the bacterial community structure over a 120-day period of bioremediation by $16 \mathrm{~S}$ rRNA genebased PCR-DGGE and found that the length of treatment 


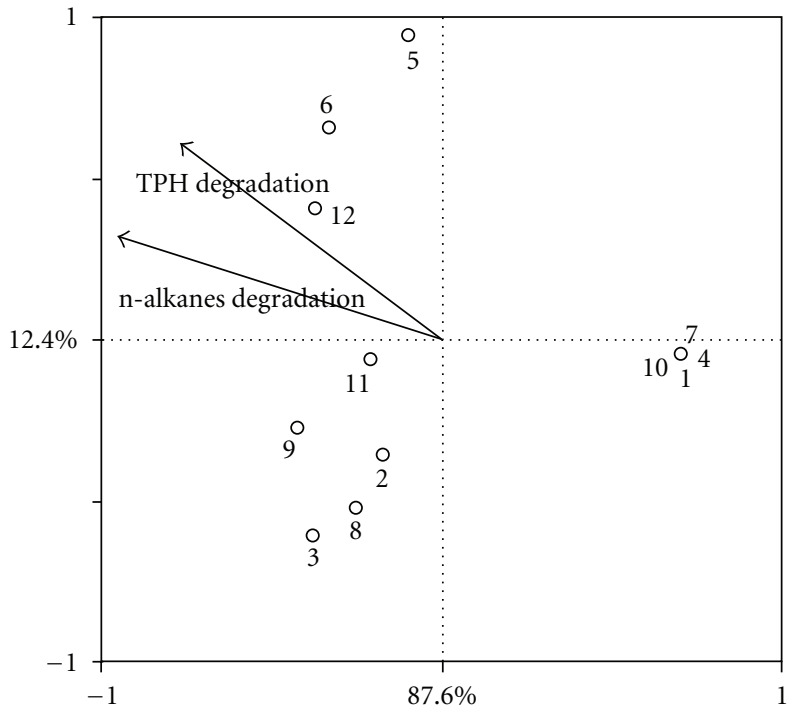

(a)

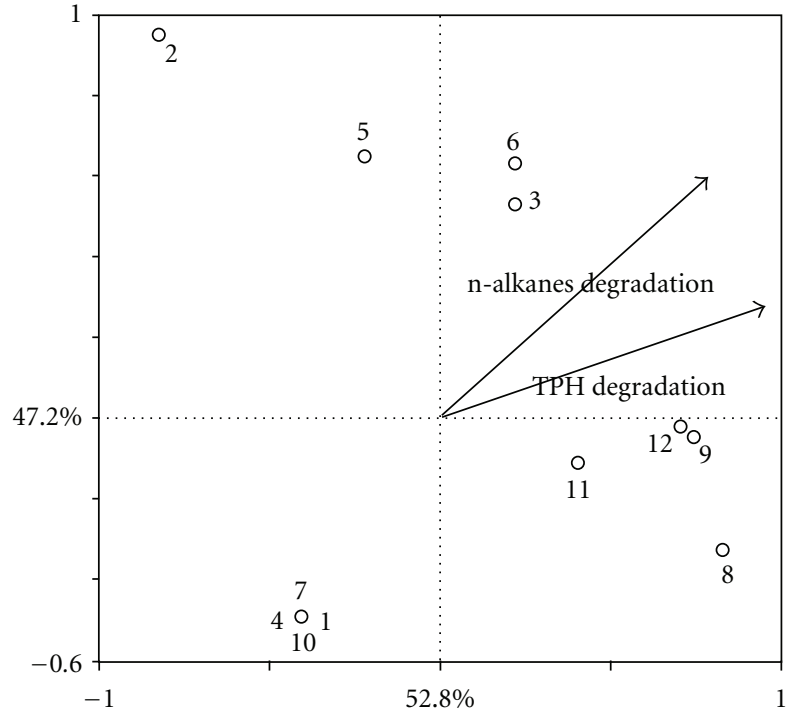

(b)

FIGURE 3: Ordination biplot displaying the first and second axis of a canonical correspondence analysis (CCA) using DGGE profiles (biological variables, open circles) and environmental variables (arrows) from Cantagalo (a) and Panelas (b) soil microcosms during bioremediation over time. (1) MNA T0, (2) MNA T60, (3) MNA T120, (4) MNAS T0, (5) MNAS T60, (6) MNAS T120, (7) BE/BA T0, (8) BE/BA T60, (9) BE/BA T120, (10) BES/BAS T0, (11) BES/BAS T60, and (12) BES/BAS T120.

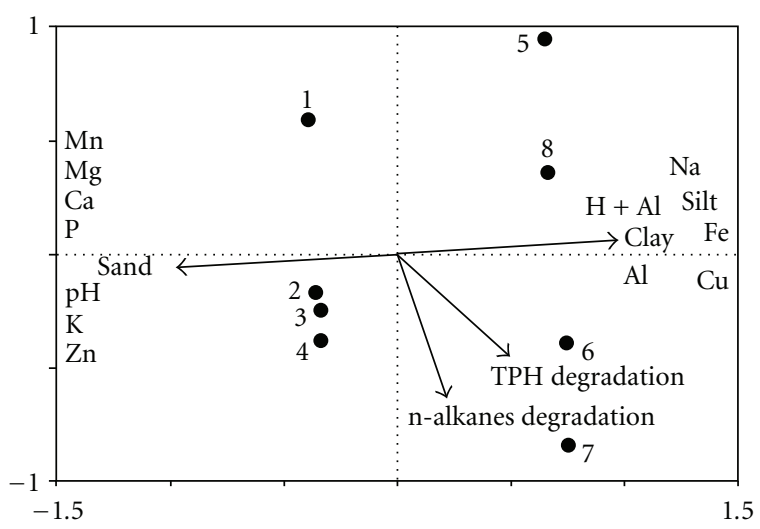

Figure 4: Ordination biplot displaying the first and second axis of a canonical correspondence analysis (CCA) using DGGE profiles (biological variables, open circles) and environmental variables (arrows) from Cantagalo and Panelas soils microcosms after 120 days of the bioremediation experiment. (1) MNA/Cantagalo, (2) MNAS/Cantagalo, (3) BE/Cantagalo, (4) BES/Cantagalo, (5) MNA/Panelas, (6) MNAS/Panelas, (7) BA/Panelas, and (8) BAS/Panelas.

was the main factor influencing the bacterial communities found in both soils we tested. This is consistent with previous work by Ciric et al. [16], which observed changes within the bacterial community during remediation in diesel-contaminated groundwater. Likewise, Piskonen et al. [35] observed the selection of specific bacterial populations during the biodegradation process in soil contaminated with polyaromatic hydrocarbons.
Through our monitoring of actinomycetes in this study, we found that the type of bioremediation treatment used was the main factor influencing the actinobacterial population in both soils. In Panelas soil, the addition of $\mathrm{NaCl}$ also resulted in changes within the actinomycetes population. This data is in line with previous work by De Azeredo et al. [36], which demonstrated that a community of mycolic-acid containing actinomycetes was affected by an increase in salinity during the treatment of industrial saline waste water.

Differences in the composition of both the soils used and the bioremediation treatment chosen contributed to the divergent results observed between Cantagalo and Panelas soil bacterial communities. CCA analysis clearly demonstrated these differences when DGGE profiles of total bacterial community of Cantagalo soil were clustered separately from the profiles of Panelas soil, likely influenced by physical and chemical compositions of each soil. Recent work by Hamamura et al. [10] suggests that the type and the concentration of nutrients in soil, as well as its physical composition and environmental parameters, influence the composition of microbial community and contribute to the variation observed in petroleum degrading populations. Thus, we believe that these soil characteristics may explain the difference in hydrocarbon mineralization rates during microbial degradation in different soils [3].

In summary, bioenrichment and bioaugmentation treatments showed slightly better results than monitored natural attenuation treatments in remediating Cantagalo and Panelas soils. Our added bacterial consortium persisted throughout the 120-day experiment and did not seem to disturb the indigenous soil microbiota, indicating these bacteria work well for bioremediation. However, the question remains of 
whether the addition of the bacterial consortium is worthwhile due to the cost of bioenrichment or bioaugmentation. A recent study by Baek et al. [17] tested five different treatments (monitored natural attenuation, biostimulation, biosurfactant addition, bioaugmentation, and a combination of the later three treatments) for the bioremediation of a soil contaminated with crude oil. They found that the TPH concentration was similar in all treatments. Thus, monitored natural attenuation was considered the method of choice because it did not result in changes in the structure of the bacterial community. Other studies have also demonstrated that monitoring the microbial community and contaminant degradation in a polluted environment might be an efficient strategy for bioremediation [37, 38]. Indeed, Couto et al. [2] concluded that monitored natural attenuation was the most efficient and the cost effective treatment (among MNA, biostimulation, and bioaugmentation) for decontamination of refinery soil contaminated with crude oil.

In terms of environmental relevance to the biomes studied, the use of bioenrichment and bioaugmentation treatments yielded slightly better results in remediating Cantagalo and Panelas soils. However, monitored natural attenuation was considered the most cost-effective approach for bioremediation of the tropical soils when an oil spill occurs in these areas.

\section{Acknowledgments}

This study was supported by grants from the National Research Council of Brazil (CNPq), CAPES, FAPERJ, and PETROBRAS.

\section{References}

[1] X. Zhu, A. D. Venosa, and M. T. Suidan, "Literature review on the use of commercial bioremediation agents for cleanup of oil-contaminated estuarine environments," EPA/600/R04/075, 2004.

[2] M. N. P. F. S. Couto, E. Monteiro, and M. T. S. D. Vasconcelos, "Mesocosm trials of bioremediation of contaminated soil of a petroleum refinery: comparison of natural attenuation, biostimulation and bioaugmentation," Environmental Science and Pollution Research, vol. 17, no. 7, pp. 1339-1346, 2010.

[3] M. Tyagi, M. M. da Fonseca, and C. C. de Carvalho, "Bioaugmentation and biostimulation strategies to improve the effectiveness of bioremediation processes," Biodegradation, vol. 22, no. 2, pp. 231-241, 2011.

[4] L. M. Whang, P. W. G. Liu, C. C. Ma, and S. S. Cheng, "Application of biosurfactants, rhamnolipid, and surfactin, for enhanced biodegradation of diesel-contaminated water and soil," Journal of Hazardous Materials, vol. 151, no. 1, pp. 155163, 2008.

[5] T. C. Lin, P. T. Pan, and S. S. Cheng, "Ex situ bioremediation of oil-contaminated soil," Journal of Hazardous Materials, vol. 176, no. 1-3, pp. 27-34, 2010.

[6] T. C. Lin, C. C. Young, M. J. Ho et al., "Characterization of floating activity of indigenous diesel-assimilating bacterial isolates," Journal of Bioscience and Bioengineering, vol. 99, no. 5, pp. 466-472, 2005.
[7] F. M. Bento, F. A. O. Camargo, B. C. Okeke, and W. T. Frankenberger, "Comparative bioremediation of soils contaminated with diesel oil by natural attenuation, biostimulation and bioaugmentation," Bioresource Technology, vol. 96, no. 9, pp. 1049-1055, 2005.

[8] D. Juck, T. Charles, L. G. Whyte, and C. W. Greer, "Polyphasic microbial community analysis of petroleum hydrocarboncontaminated soils from two northern Canadian communities," FEMS Microbiology Ecology, vol. 33, no. 3, pp. 241-249, 2000.

[9] R. Margesin, D. Labbé, F. Schinner, C. W. Greer, and L. G. Whyte, "Characterization of hydrocarbon-degrading microbial populations in contaminated and pristine Alpine soils," Applied and Environmental Microbiology, vol. 69, no. 6, pp. 3085-3092, 2003.

[10] N. Hamamura, S. H. Olson, D. M. Ward, and W. P. Inskeep, "Microbial population dynamics associated with crude-oil biodegradation in diverse soils," Applied and Environmental Microbiology, vol. 72, no. 9, pp. 6316-6324, 2006.

[11] M. A. Providenti, H. Lee, and J. T. Trevors, "Selected factors limiting the microbial degradation of recalcitrant compounds," Journal of Industrial Microbiology, vol. 12, no. 6, pp. 379-395, 1993.

[12] M. Romantschuk, I. Sarand, T. Petänen et al., "Means to improve the effect of in situ bioremediation of contaminated soil: an overview of novel approaches," Environmental Pollution, vol. 107, no. 2, pp. 179-185, 2000.

[13] A. Backman, N. Maraha, and J. K. Jansson, "Impact of temperature on the physiological status of a potential bioremediation inoculant, Arthrobacter chlorophenolicus A6," Applied and Environmental Microbiology, vol. 70, no. 5, pp. 2952-2958, 2004.

[14] S. A. Huws, A. J. McBain, and P. Gilbert, "Protozoan grazing and its impact upon population dynamics in biofilm communities," Journal of Applied Microbiology, vol. 98, no. 1, pp. 238-244, 2005.

[15] J. D. Van Elsas and F. G. H. Boersma, "A review of molecular methods to study the microbiota of soil and the mycosphere," European Journal of Soil biology, vol. 47, no. 2, pp. 77-87, 2011.

[16] L. Ciric, J. C. Philp, and A. S. Whiteley, "Hydrocarbon utilization within a diesel-degrading bacterial consortium," FEMS Microbiology Letters, vol. 303, no. 2, pp. 116-122, 2010.

[17] K. H. Baek, B. D. Yoon, B. H. Kim et al., "Monitoring of microbial diversity and activity during bioremediation of crude oil-contaminated soil with different treatments," Journal of Microbiology and Biotechnology, vol. 17, no. 1, pp. 67-73, 2007.

[18] Y. S. Kang, Y. J. Park, J. Jung, and W. Park, "Inhibitory effect of aged petroleum hydrocarbons on the survival of inoculated microorganism in a crude-oil-contaminated site," Journal of Microbiology and Biotechnology, vol. 19, no. 12, pp. 1672-1678, 2009.

[19] V. M. Alvarez, S. C. C. Dos Santos, R. D. C. Casella, R. L. Vital, G. V. Sebastin, and L. Seldin, "Bioremediation potential of a tropical soil contaminated with a mixture of crude oil and production water," Journal of Microbiology and Biotechnology, vol. 18, no. 12, pp. 1966-1974, 2008.

[20] EPA 8015C, “Nonhalogenated Organics using GC/FID," EPA, Revision 3, 2000.

[21] H. P. Caputo, "Propriedades das partículas sólidas do solo," in Mecânica dos Solos e Suas Aplicações, pp. 23-39, Livros Técnicos e Científicos Editora S.A., Rio de Janeiro, Brasil, 1973.

[22] EPA 8015D, “Nonhalogenated Organics using GC/FID,” EPA, 
Revision 4, 2003.

[23] L. Seldin and D. Dubnau, "Deoxyribonucleic acid homology among Bacillus polymyxa, Bacillus macerans, Bacillus azotofixans, and other nitrogen-fixing Bacillus strains," International Journal of Systematic Bacteriology, vol. 35, no. 2, pp. 151-154, 1985.

[24] H. Heuer and K. Smalla, "Application of denaturing gradient gel electrophoresis and temperature gradient gel electrophoresis for studying soil microbial communities," in Modern Soil Microbiology, J. D. van Elsas, E. M. H. Wellington, and J. T. Trevors, Eds., pp. 353-373, J. Marcel Dekker, New York, NY, USA, 1997.

[25] U. Nübel, B. Engelen, A. Felsre et al., "Sequence heterogeneities of genes encoding $16 \mathrm{~S}$ rRNAs in Paenibacillus polymyxa detected by temperature gradient gel electrophoresis," Journal of Bacteriology, vol. 178, no. 19, pp. 5636-5643, 1996.

[26] H. Heuer, M. Krsek, P. Baker, K. Smalla, and E. M. H. Wellington, "Analysis of actinomycete communities by specific amplification of genes encoding 16S rRNA and gelelectrophoretic separation in denaturing gradients," Applied and Environmental Microbiology, vol. 63, no. 8, pp. 3233-3241, 1997.

[27] S. El Fantroussi and S. N. Agathos, "Is bioaugmentation a feasible strategy for pollutant removal and site remediation?" Current Opinion in Microbiology, vol. 8, no. 3, pp. 268-275, 2005.

[28] T. J. Gentry, K. L. Josephson, and I. L. Pepper, "Functional establishment of introduced chlorobenzoate degraders following bioaugmentation with newly activated soil: Enhanced contaminant remediation via activated soil bioaugmentation," Biodegradation, vol. 15, no. 1, pp. 67-75, 2004.

[29] N. Sood, S. Patle, and B. Lal, "Bioremediation of acidic oily sludge-contaminated soil by the novel yeast strain Candida digboiensis TERI ASN6," Environmental Science and Pollution Research, vol. 17, no. 3, pp. 603-610, 2010.

[30] M. Arenskötter, D. Bröker, and A. Steinbüchel, "Biology of the metabolically diverse genus Gordonia," Applied and Environmental Microbiology, vol. 70, no. 6, pp. 3195-3204, 2004.

[31] S. J. Lu, H. Q. Wang, and Z. H. Yao, "Isolation and characterization of gasoline-degrading bacteria from gas station leakingcontaminated soils," Journal of Environmental Sciences, vol. 18, no. 5, pp. 969-972, 2006.

[32] K. Przybulewska, A. Wieczorek, A. Nowak, and M. Pochrzaszcz, "The isolation of microorganisms capable of phenol degradation," Polish Journal of Microbiology, vol. 55, no. 1, pp. 63-67, 2006.

[33] P. Quatrini, G. Scaglione, C. De Pasquale, S. Riela, and A. M. Puglia, "Isolation of Gram-positive n-alkane degraders from a hydrocarbon- contaminated Mediterranean shoreline," Journal of Applied Microbiology, vol. 104, no. 1, pp. 251-259, 2008.

[34] X. Zhuang, Z. Han, Z. Bai, G. Zhuang, and H. Shim, "Progress in decontamination by halophilic microorganisms in saline wastewater and soil," Environmental Pollution, vol. 158, no. 5, pp. 1119-1126, 2010.

[35] R. Piskonen, M. Nyyssönen, T. Rajamäki, and M. Itävaara, "Monitoring of accelerated naphthalene-biodegradation in a bioaugmented soil slurry," Biodegradation, vol. 16, no. 2, pp. 127-134, 2005.

[36] L. A. I. De Azeredo, C. D. Da Cunha, A. S. Rosado et al., "New group-specific $16 \mathrm{~S}$ rDNA primers for monitoring foaming mycolata during saline waste-water treatment," Biotechnology
Letters, vol. 28, no. 6, pp. 447-453, 2006.

[37] P. L. Bjerg, N. Tuxen, L. A. Reitzel, H. J. Albrechtsen, and P. Kjeldsen, "Natural attenuation processes in landfill leachate plumes at three Danish sites," Ground Water.

[38] K. S. Jørgensen, J. M. Salminen, and K. Björklöf, "Monitored natural attenuation," Methods in Molecular Biology (Clifton, N.J.), vol. 599, pp. 217-233, 2010. 

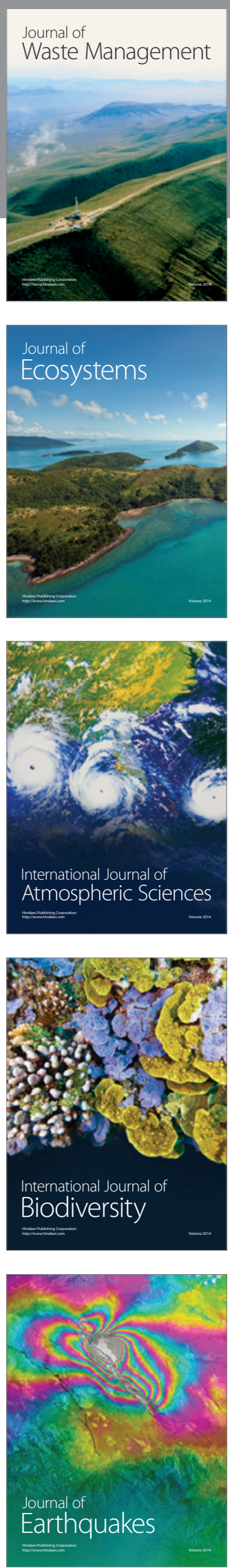
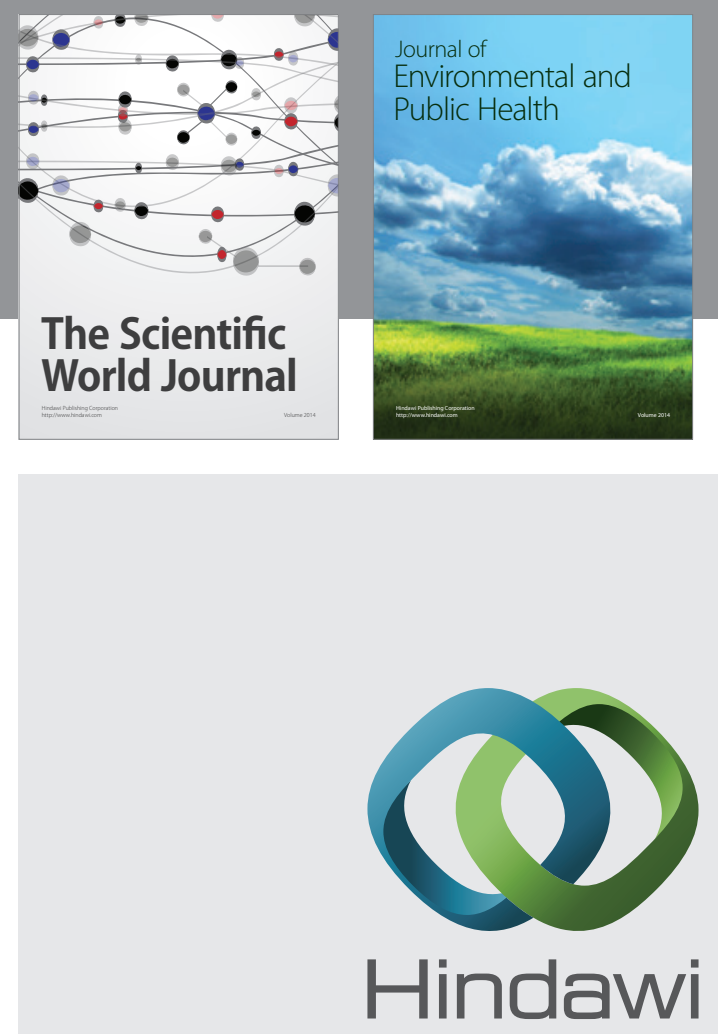

Submit your manuscripts at

http://www.hindawi.com
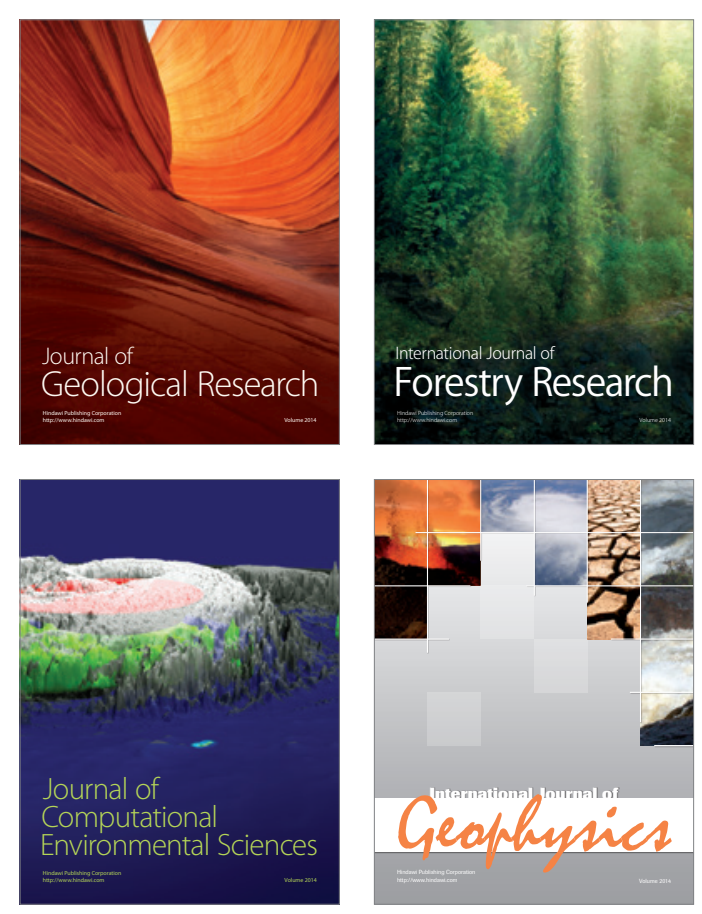
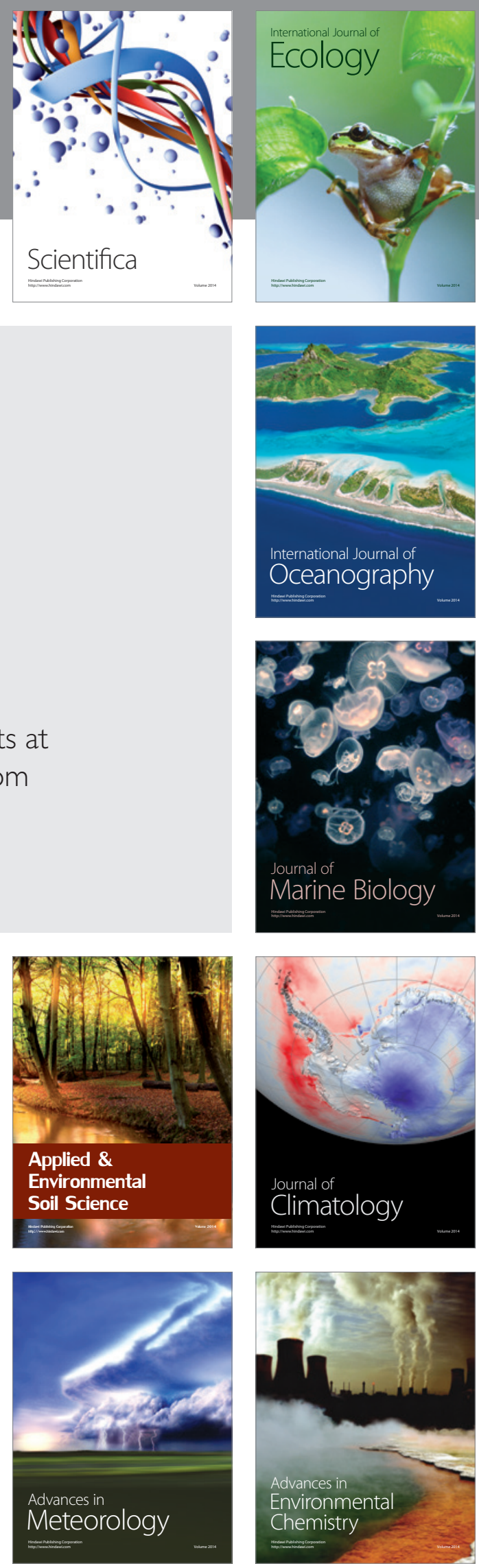